\title{
A MULTIMODAL ANALYSIS OF COMPLIMENT SEQUENCES IN EVERYDAY ENGLISH INTERACTIONS
}

\author{
Tiina Keisanen and Elise Kärkkäinen
}

\begin{abstract}
This study offers a multimodal analysis of turns in everyday English interactions that are used for making compliments, i.e. for positively evaluating the appearance, personal qualities or actions of (a) co-present participant(s) in the present situation. We first identify the most frequent linguistic formats recurrently occurring in compliments in our data. We then focus on the sequential interactional analysis of compliment sequences, i.e. the production of the compliment and the response it receives. While a range of bodily-visual displays and prosodic features can be identified as co-constructing compliment activity, we argue that gaze direction has a specific role in the production of both compliments and their responses. The data come from a database of approximately 8 hours of video-recorded casual face-to-face conversations in English. The study employs the methodology of conversation analysis, maintaining that social interaction in face-to-face conversations is a multimodal achievement, where participants' use of language, embodied actions and material objects are variously combined to build coherent courses of action (Goodwin 2000). The aim of the study is to provide a description of how embodied actions enter into the design of social action formats for compliments.
\end{abstract}

Keywords: Compliments; Conversation analysis; Embodied actions; Evaluation; Language in use; Social action format.

\section{Introduction: Vocal and embodied formats of evaluation in English interaction}

In general terms, evaluation refers to the speaker's expression of valenced (positive/negative) judgments in terms of goodness, beauty, or some other sociocultural attribute (Keisanen \& Kärkkäinen 2014). This study offers an analysis of sequences of turns that are used for making, and responding to, positive evaluations of appearance, some personal quality, or actions of (a) co-present participant(s) in the present situation. The clear majority of such positive evaluations in the current database are treated by the participants as compliments. These variably arise from prior discourse (e.g. You guys are so good at taking pictures. where the turn is a response to a prior telling about taking photographs), while in other cases the objects of evaluation may become 'noticed' (Schegloff 2007; Keisanen 2012) as they are available in the immediate material context (e.g. That's a really cute little top,). After providing a linguistic overview of compliments in the database, we focus on their interactional analysis. 
In the present study, then, we define compliments as actions that positively evaluate the appearance, personal qualities, or actions of a co-present participant. As such, compliments can be thought of as a particular type of assessment. Assessments have been approached in previous research as actions used to evaluate persons, objects and events described in conversation (Pomerantz 1984; Goodwin \& Goodwin 1987, 1992). As a rigorous or even a working definition of compliments is lacking in the conversation-analytical literature, Shaw \& Kitzinger (2012) decide to limit their "collection of compliments to those designed as positive assessments" (2012: 241; see also Pomerantz 1978). Assessments can be considered the more general category covering a wide range of evaluative turns in interaction; the difference between the two actions is that compliments target something 'belonging' to, or associated with, a particular co-present participant, while assessments are not restricted in this way. ${ }^{1}$ In addition, and importantly, the two action types differ in the way they are responded to, and in their preference structure. Pomerantz (1984) establishes that reactions to assessments typically consist of second assessments, which may be designed to display different degrees of agreement or disagreement with prior first assessments. Among the means discussed are upgraded second assessments, which function as displays of strong agreement. However, such upgraded agreements are rare in responses to compliments. This is because responses to compliments are influenced by two competing preference systems: Pomerantz (1978: 81-82) shows how, for recipients, the preference on the one hand to agree with and/or accept the compliments and on the other hand to avoid selfpraise are in potential conflict (see Golato 2002 for compliment responses in German). Pomerantz (1978) further demonstrates that recipients have different linguistic turndesign opportunities for dealing with these two conflicting preferences: They are observed to insert praise downgraders, engage in reference shifts or respond to a compliment with another, reciprocated compliment.

More generally, in describing compliments, this study contributes to research on recurrent and routinized conversational patterns in interaction, which originate in the interactional needs of participants (see e.g. Couper-Kuhlen \& Thompson 2005). Previous research on such conversational patterns, or 'social action formats' (Fox 2000, 2007), has mainly focused on recurrent linguistic formats for enacting particular actions. For example, assessments produced in social interaction have been found to regularly follow a recurrent linguistic template, expressed as [it] + [copula] + [adverbial intensifier] + [assessment term] (Goodwin \& Goodwin 1992: 162). Goodwin \& Goodwin (1992) observe that discourse participants can modify the linguistic design of their assessment and thereby display their different access to phenomena being assessed, for example, through their choice of tense or evidential materials (see also Heritage and Raymond 2005; Mondada 2009). Compliments have likewise been observed to contain semantically positive materials and to display such a high degree of conventionalization that they amount to 'formulas' (Manes \& Wolfson 1981) (see Section 3.1 for a more detailed account).

While we approach grammar as an inventory of format-like patterns emerging from interaction, this view is diversified, and complicated, by the inclusion of bodily actions in the analysis of social action formats (see Kärkkäinen \& Keisanen 2012; Rauniomaa \& Keisanen 2012). In addition to language, embodied actions such as gestures, gaze or body posture, have been shown to have a significant role in the design

\footnotetext{
${ }^{1}$ We thank the editors for helping us to explicate this difference.
} 
or reception of speaker turns in interaction (e.g. Schegloff 1986; Goodwin \& Goodwin 1992) and in the organization of action and participation more generally (e.g. Goodwin 2000). With respect to embodied actions in assessments, body position, gestures and facial expressions may be used to maintain or establish the participants' reciprocal involvement in, or detachment from, the ongoing assessment activity (Goodwin \& Goodwin 1987, 1992; Haddington 2006; Ruusuvuori \& Peräkylä 2009). Haddington (2006) discusses the use of gaze in assessment sequences, and finds that mutual gaze is typically established during agreeing second assessments, while cut-off gaze precedes a disagreeing response to a prior assessment. As observations about the embodied actions in compliment sequences are non-existent, the aim of this study is to provide a description of how embodied actions enter into the design of social action formats for compliments.

The study is organized as follows. Section 2 presents the database of the present study as well as briefly outlines the methodology adopted. Section 3 provides an analysis of the data. Section 3.1 presents the linguistic format for compliments, while Section 3.2 includes the sequential and multimodal analysis of compliments (3.2.1) and how they are received by their recipients (3.2.2), showing how compliment activity is a collaborative multimodal achievement between the participants. Section 4 presents our conclusions.

\section{Materials and methodology}

The data come from a database of about 8 hours of video-recorded casual face-to-face conversations in English, from the Oulu Video Corpus of English at the University of Oulu, and a video recording called 'Farmhouse'. ${ }^{2}$ The majority of speakers are native speakers of English, mainly American English. Two of the recordings also include nonnative speakers of English. There are a total of 27 different speakers, four of which are non-native speakers. Rather than focusing on potential cross-cultural differences or differences between native and non-native speakers, however, at the initial stages of multimodal research into action formation we do not wish to automatically assume that bodily-visual features of interaction are culturally dependent. Further, as research on second-language conversations has shown, participants' focus in such conversations, as in any conversation, is on the successful progression of their activities rather than on their possibly partial linguistic skills (Wagner \& Gardner 2004: 3).

The data are transcribed by following the Discourse Transcription conventions (Du Bois et al. 1993), where the intonation unit (IU) forms the basic unit of transcription (such that one line equals one intonation unit). The relevant embodied actions and features of the material context are mainly shown through screen shots, but some key actions are also included in the transcripts (in SMALL CAPS). Prosodic features have been auditorily identified, but for clarity only the most prominent prosodic features (e.g. clearly higher pitch or louder volume) have been transcribed. See Appendix A for transcription symbols.

As research to date has mainly focused on evaluations of reported past events

these data.

${ }^{2}$ We are grateful to Barbara Fox, University of Colorado, for allowing us access to 
and past actions (Lindström \& Mondada 2009), we wanted to map out all types of evaluations directed at the co-present participants in the database. We therefore identified all the sequences in which the participants produced some kind of evaluation of their co-participant(s), relating to, for example, their appearance, personal qualities or actions. Not surprisingly, such evaluations were found to cover a broad continuum from positive to negative. In interactional terms, the actions implemented with such turns included complaints, reprimands, negative assessments, teases, compliments and positive assessments with the assessable being not only the recipient but also other participants, including the current speaker. The interactional analyses offered below focus specifically on compliments and how they are received by other discourse participants.

The study employs the methodology of conversation analysis (see e.g. Hutchby $\&$ Wooffit 2008). As mentioned above, embodied actions have been observed to have a significant role in the organization of action and participation in interaction, to the degree that face-to-face interaction may most profitably be understood as a multimodal achievement. In addition, along with an already substantial body of research, we maintain that participants' use of embodied actions and linguistic resources is designed to variously combine and interact with the material setting (including, for example, orientation to and handling of material objects) in order to build locally relevant actions (Streeck, Goodwin \& LeBaron 2011: 2; Goodwin 2000). Multimodality conceived in this broad sense has an important role in the construction of social action formats, which we will further discuss below. Our findings will provide further support for the understanding of grammar as "public embodiment of action" (Fox 2007: 310).

\section{Analysis}

The section begins with a linguistic analysis of compliments (Section 3.1) and identifies the most frequent linguistic format for their construction. Section 3.2 will then focus on the multimodal analysis of compliments and their responses. In addition to linguistic forms, the analyses will explore the prosody and the embodied actions deployed by the participants, and how these different modalities co-construct compliment actions and their responses. We show how prosody and embodied actions (e.g. gaze, gestures, body posture) have a central role in the production of both.

\subsection{A linguistic format for making compliments}

As mentioned above, we initially included all actions that appeared to be doing some kind of evaluating of co-present participants, whether positive or negative, thus accumulating a total of 58 cases (in all 60 utterances). The linguistic forms of these actions showed a variety of subjects, verb forms and tenses, as well as a range of different kinds of evaluating material. ${ }^{3}$ Of these, a total of 21 were compliments. In

${ }^{3}$ It was at times difficult to draw a line between, on the one hand, positive assessments (We're so different, ..it's awesome) and compliments (that's amazing), and, on the other, negative assessments (Yeah you're boring too), complaints (Oh, you suck so bad for that) and reprimands (That is bad Jason). The sequential context of course disambiguates in most cases, as positive assessments can be made of co-present participants that are not at the same time, or primarily, praising or complimenting 
what follows, we discuss the most frequent linguistic formats for making them.

Perhaps unsurprisingly, the most common subject in the compliments in the data is the second-person pronoun you (11 instances; see also Shaw \& Kitzinger 2012: 222), which is almost always used for singular reference (with one occurrence of you guys and one of you for plural reference); speakers mostly directed their evaluations directly to the person being complimented, as in You're the perfect guy. It is relatively seldom that they evaluate a participant in front of another using a third-person singular pronoun, as in He's got an impressive bookshelf said to a visitor about a flat mate who is also present. On the other hand, there are two cases of compliments done with an adjective or noun phrase only, as in Excelle=nt. Alternatively, participants also evaluate the actions or personal attributes of another participant by using the demonstrative singular pronoun that (4 times), as in That's amazing./ That's a really cute little top. We can summarize, then, that the most frequent subject in the data is the second-person singular you, with that next in frequency (see also Scheibman 2001).

The verb types in the data are not highly varied and are relatively small in number, comprising 7 different verbs, with a very small distribution (1-2 tokens) for almost all but be (13 tokens; this is in accordance with Scheibman's 2001 findings on the most frequent verb types in American English conversation). There were only a handful of evaluative verbs like love or like (each with only one token), or even look + evaluative item (2 tokens: Nellie you look gorgeous.). This leads us to conclude that the format favored by speakers tends to include the relational verb be over other verbs.

We can further briefly note that the prevalent verb tense is the present tense (14 instances), as is appropriate for evaluations directed at the present-time/ongoing actions or attributes of co-present participants. Most of the examples above serve to illustrate this. Occasionally, participants evaluate some immediately preceding action of a coparticipant with a simple past tense (Thank you Alex, that was lovely.), some future action with a future auxiliary (You will make the perfect manager.), or some hypothetical action with a modal auxiliary (You'd do good at Weight Watchers.).

It is conceivable that the explicitly evaluative material of the actions in focus could be of a range of different expression types, but it turned out that most commonly it consists of a simple adjective (13 instances) or a noun phrase (7). It is worth noting that by far the most commonly used verb, relational or copula be, is in itself not evaluative, but is then combined with a positive evaluative adjectival complement (That was really kind.) or a noun phrase (That's a really cute little top, I really like it.).

In summary, the most frequent linguistic formats that we can extract from the data for compliments are as follows. First, the format for compliments includes the second-person pronoun you, while copula be is the most common verb and most frequently appears in the present tense. The evaluative item is in almost all cases either an adjective in its base form or a noun phrase.

\section{Compliments: [you $]+[$ are $]+[($ highly $)$ positive ADJ/NP]}

these participants (Shaw \& Kitzinger 2012: 217), while negative evaluations may not be doing complaining at the same time (e.g. they may be done in jest). But even so the above action pairs come very close to each other; Pomerantz (1978: 82), for one, mentions that compliments may have the status of assessments, as the recipient can disagree or agree with the complimentary assertion. 
It is also worth noting that there are compliments in the data that are not of the above format, as utterances like You've been everywhere (see Example 6 below) also positively evaluate the co-participant's actions and personal qualities (as someone who has a wide working experience). Yet there is a clear tendency for certain recognizable linguistic formats to be frequently used to carry out compliments. This finding is supported by the seminal treatment of compliments by Manes and Wolfson (1981), who similarly establish the semantically and syntactically formulaic nature of compliments. The authors state (1981: 122), for example, that second-person pronouns and demonstratives occur in 75 per cent of all the 686 compliments in their data, and that 'indirect compliments' with he or she as subjects are rare in their corpus. However, there are some distinct differences between their data and ours. They find that just two verbs, like and love, occur in roughly 20 per cent of their compliments (see the figure in Manes and Wolfson 1981: 121), but in our (admittedly small) database those two verbs occur seldom (each only once). They also state that 80 per cent of the attested compliments are of the adjectival type (NP is/looks (really) ADJ, as in Your hair looks nice.), the remaining 20 per cent containing either a verb, a noun phrase or an adverb. The most important difference, however, is that of the nine syntactic formulas that they give for compliments (1981: 120-121), none resembles our format above. ${ }^{4}$ The only one that comes close is PRO is (really) (a) ADJ NP (as in That is a nice piece of work.), but this formula does not occur frequently in our data (as discussed above).

It is worth noting that Manes and Wolfson's database was not collected by recording naturally-occurring interactions, but the authors and their students wrote down any compliment that they heard. It is thus likely that the data collectors were not very attuned to the sequential position of the "expressions of positive evaluation" (1981: 116) that they heard. The authors observe (1981: 126) that compliments are often conversation-initial (i.e. occur at the beginning of a social encounter) and a compliment/response exchange may constitute an entire speech event. Compliments are further claimed to be independent from what precedes. But, as we will see below in Section 3.2, neither of these observations holds for our data, as compliments are also frequently found in the midst of extended conversations, and may arise from the ongoing interaction.

Having established that there is a preference for certain recurrent linguistic forms in the compliments in the data, we now proceed to look at how exactly they are produced in the sequentially unfolding interaction.

\subsection{Multimodal analysis of compliment sequences}

In the following we offer a sequential analysis of compliments in our data and also discuss the role of embodied actions in the construction of compliments and their responses.

${ }^{4}$ In Manes and Wolfson's data (1982: 120), $53.6 \%$ of the compliments make use of a single syntactic pattern: NP is/looks (really) ADJ (e.g. Your hair looks nice), while two other syntactic patterns are also very common: I (really) like/love NP (e.g. I love your hair), and PRO is (really) (a) ADJ NP (e.g. That is a nice piece of work). 


\subsubsection{Compliments}

In order to explore the multimodal production of compliments, we will here provide three examples of compliments in reactive or responsive positions. Even though previous research appears to have focused largely on first-position compliments that come "out of the blue" (Manes \& Wolfson 1981; Golato 2002; see also Example 4 below for a potential case of first-position compliment: But you look really good in the camera=.), reactive compliments were more frequent in our data. They are typically responsive to the co-participant's actions, descriptions or tellings that have become available in the immediately prior turns or interaction. These descriptions or tellings do not typically include an explicit evaluative dimension as such, but they are conducive to being assessed positively. The embodied actions and prosody of the participants proffering such compliments range from highly animated displays of affect, to more subdued displays of bodily conduct and prosodic encoding. It is only the role of gaze that emerges as a constant bodily-visual feature in the data: Those producing compliments gaze directly at the recipient, who may or may not respond to the gaze.

The following is an example of a compliment after a question-answer sequence that may be seen as somehow leading to the compliment turn. The three participants are exchange students at a university and are socializing in the kitchen of a hall of residence. Guy is Australian (on the left in the screen shots below), Robert is American (in the middle) and Rukmini is from South Africa (on the right). Robert and Guy are flat mates, while Rukmini has met Robert but not Guy before. The three have been discussing what they would like to do for a living after finishing their studies. Guy has answered Rukmini's question that he wants to be a teacher and then a principal. Rukmini's reaction to this has been one of some surprise (Are you serious?). Guy has just also rather emphatically proclaimed, three times in fact, that he loves people management. Rukmini then asks Guy if he engages in judging people. Three symbols $(*, \%$ and $\&)$ are used to indicate the starting-point for gaze and bodily conduct in relation to talk as well as the location of screen shots.

Oulu Video Corpus of English, 012 Oh My God <00:17:40〉

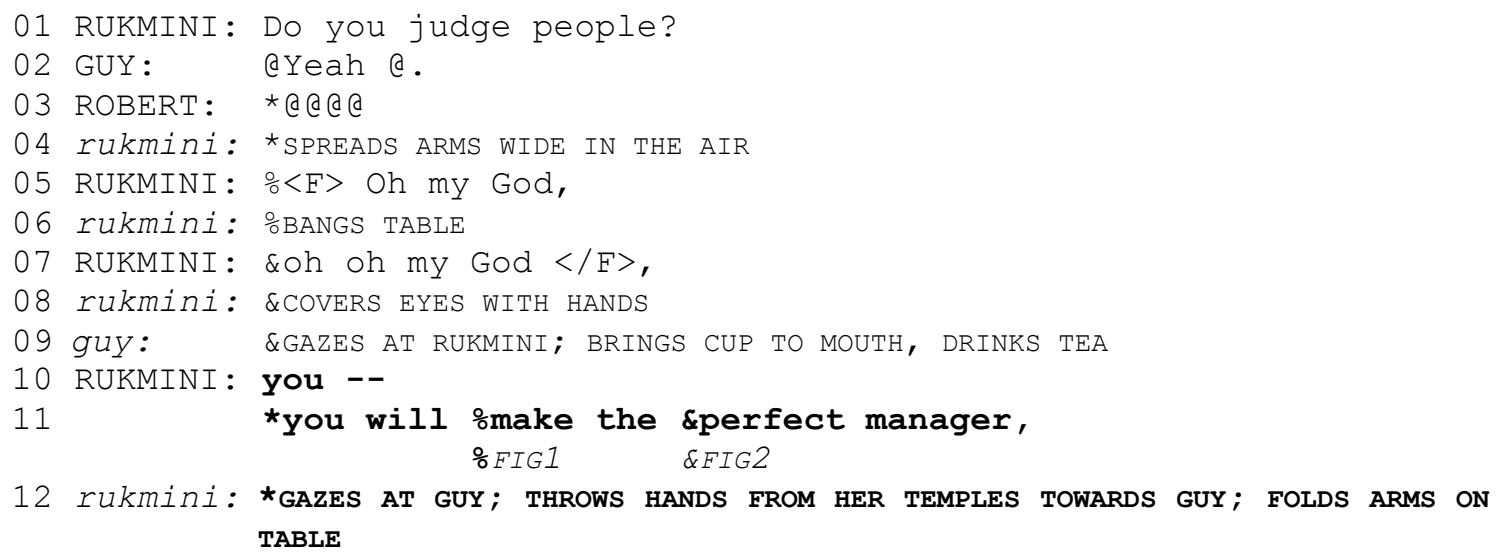




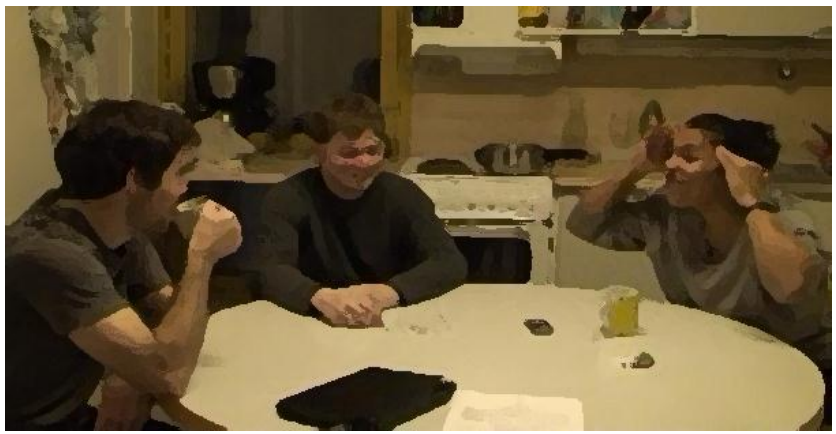

Figure 1. Rukmini raises her hands to her temples

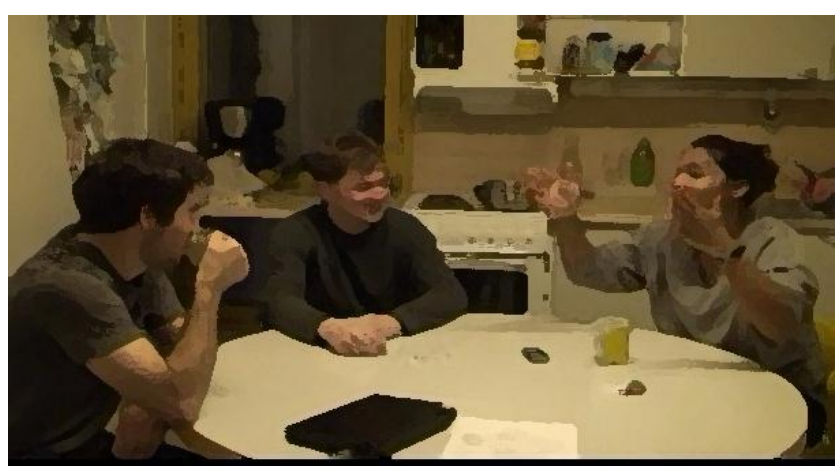

Figure 2. Rukmini throws her hands towards Guy

13 RUKMINI: *because I do that as well?

14 rukmini: * GLANCES AT ROBERT

15 guy: *LOOKS DOWN; BRINGS CUP DOWN TO TABLE

16 ROBERT: Mm.

It seems as though the question in line 1 acts as a preliminary to the subsequent compliment. Guy's positive response triggers an extremely marked response from Rukmini, who first produces two emphatic exclamations Oh my God, oh my God, (lines 4-8) in very loud voice and relatively high pitch, accompanied by animated gesturing of hands and arms. She then immediately continues with the compliment you-- you will make the perfect manager. The verbal compliment is produced as an extreme case formulation (Pomerantz 1986) suggesting an almost exaggerated view of Guy's aptitude. The prosodic and embodied production of the compliment matches the words spoken. It has an animated prosody, i.e. louder than normal voice and a strong stress on perfect. It is also produced through highly animated bodily actions. Rukmini first dramatically raises her hands to her temples (Figure 1), then forcibly releases her hands towards Guy (Figure 2), and finally brings her arms to home position on the table. While producing line 11 she also makes direct eye contact with Guy, who is at this point also gazing at her. Speaker gaze has been seen as one relatively strong factor in pursuing recipient response (see, e.g. Bavelas et al. 2002; Stivers and Rossano 2010), and we may argue that the compliment producer is thus seeking a response from the recipient.

In sum, the compliment in Example (1) is not only implemented verbally but coconstructed through multiple modalities, each contributing to an 'ardent' affective stance display by the compliment speaker (see Du Bois and Kärkkäinen 2012 and Couper-Kuhlen 2012 for affect and stance). Prosody and embodied actions have a 
central role in the management of affect in this example. As it happens, the emphatic and affect-laden compliment is not responded to verbally at all, and even the bodilyvisual reception is minimal and exhibits withdrawal (Guy brings his cup down to the table and looks down). It is possible that the compliment is deemed as not sincere (and even ironic), and the recipient chooses to bypass it. In Section 3.2.2, we will examine more closely the typically minimal verbal responses and impassive bodily reception of compliments in the data.

The following compliment is a reaction to a longer telling of the co-participant. At the start of the extract, which takes place only about half a minute after Example (1), Guy is describing how different he is as a reader of books from his flat mate Robert: He is a reader who is interested in the relationships between the characters, as well as themes, bodies and images, in a book. This seems to reinforce Rukmini's already positive image of Guy as a potential manager and triggers another compliment from her.

(2) Oulu Video Corpus of English, 012 Oh My God 〈00:18:16>
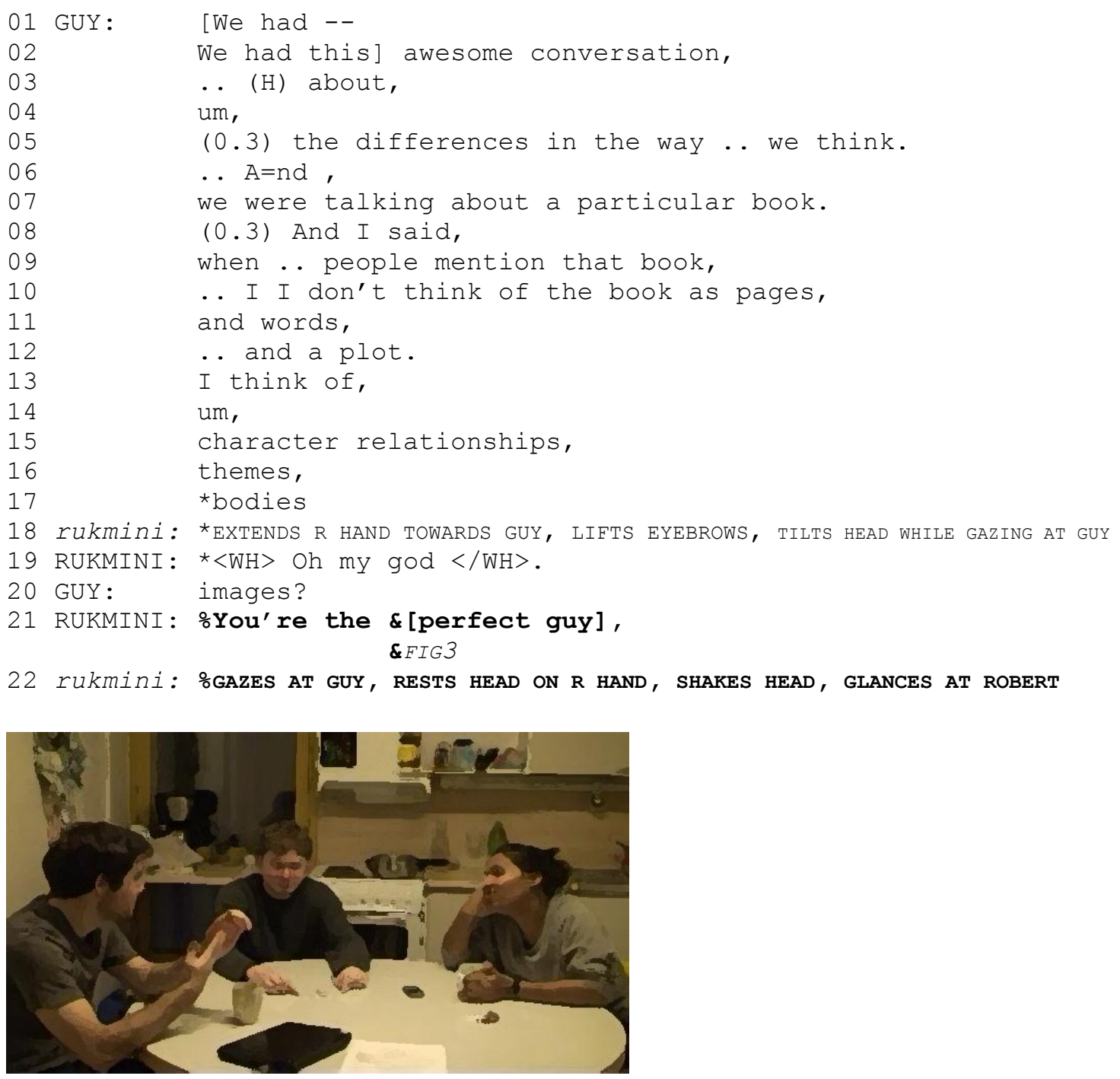

Figure 3. Rukmini gazes at Guy, leans towards right hand and shakes head 


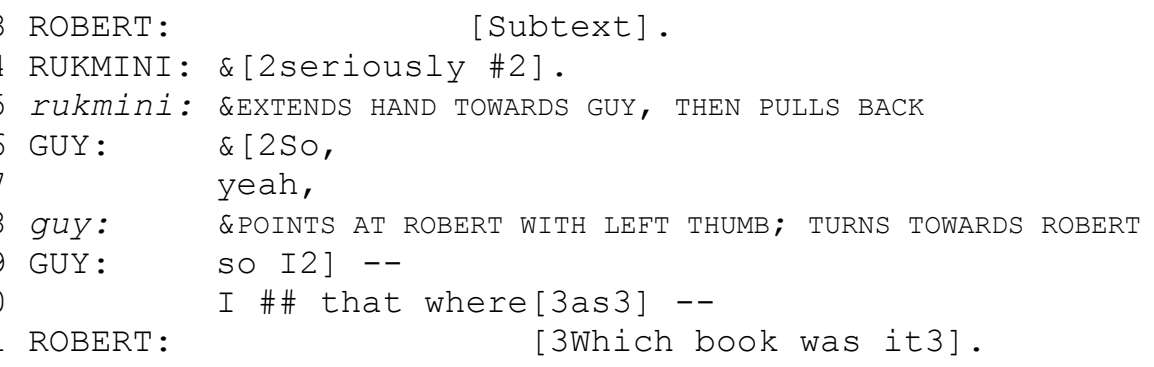

This compliment, which further elaborates on Rukmini's view of Guy as particularly apt to become a manager (as he is attuned to the relationships between people), resonates with the one in Example (1) in its wording, but not in its prosody or bodily production. Rukmini starts to produce the compliment already in lines 18-19: She utters the exclamation Oh my God in a barely audible whisper and simultaneously extends her right hand towards Guy, tilting her head and lifting her eyebrows. These embodied actions appear to imply something like "there you see", possibly in acknowledgement of her earlier positive view of Guy. She then produces the actual compliment You're the perfect guy, (Figure 6) while resting her head on her right hand and shaking her head, thus intensifying the action somewhat (McClave 2000). She also gazes at Guy intently while producing the compliment. Prosodically the turn is produced with a "dreamy" tone of voice characterized by rather soft voice quality and a pitch starting high in the speaker's range and ending in mid rather than low pitch.

We can now conclude that the marked prosodic and bodily production of what is verbally again an extreme case formulation contributes to a stance that is a little affected and possibly even flirtatious. Rukmini further pursues a response from Guy by gazing at him during the compliment turn and upgrading the compliment by tagging on seriously (line 24) and extending her hand towards Guy. However, again no response is forthcoming: There is no verbal acknowledgement from Guy and he bypasses the compliment by continuing with his telling on line 26 and turning towards Robert.

The following is an example of a compliment that is responsive to how well the recipient has performed earlier in the interaction. The dinner was recorded in Australia. Rose, the mother, compliments Alex, her son, on the quality of the dinner he has prepared for the family. The participants have just finished eating and Alex is here clearing the table in the dining room. He is turning away from the table to take two glasses to the kitchen when Rose comes from the kitchen.

(3) Oulu Video Corpus of English, 008 Piano Dinner 〈00:39:20>

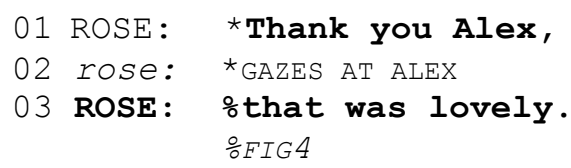




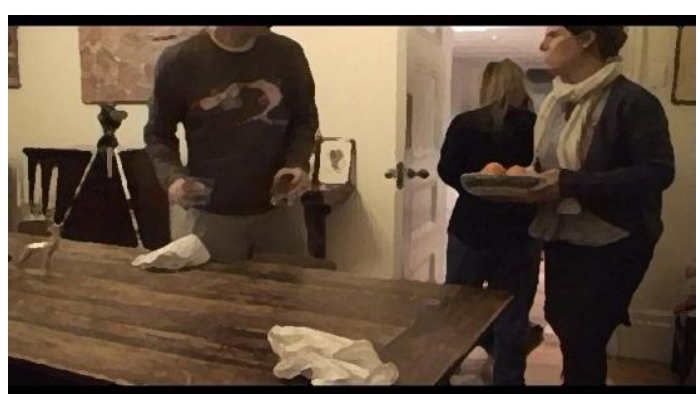

Figure 4. Rose gazing at Alex while producing compliment
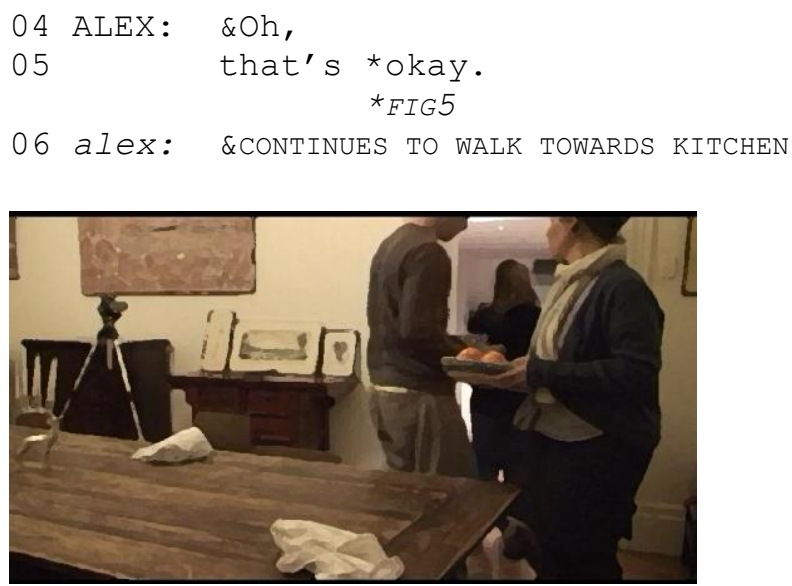

Figure 5. Alex continuing towards kitchen

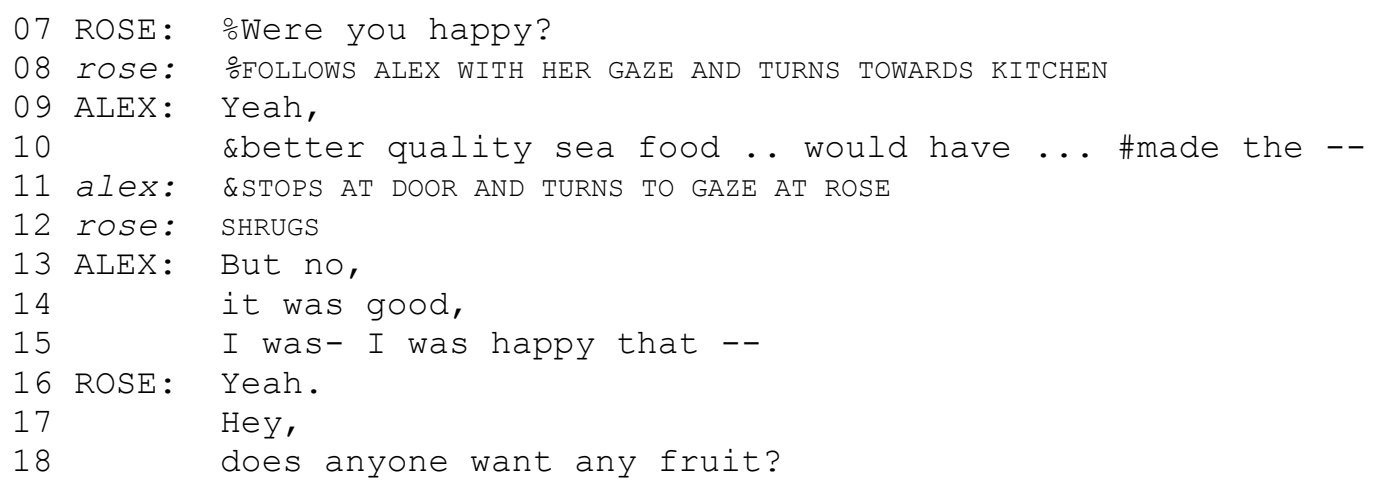

The turn produced by Rose combines a thanking action with a compliment. The latter makes use of the slightly less formulaic pattern (see Section 3.1) of that followed by a past tense form of $b e$ and an evaluative adjective. This may be due to the fact that the recipient has already been nominated in the first part of the turn (and you already appeared as object in thank you). When Rose produces the turn, she is gazing fully and rather intently at Alex. However, Alex's uninterrupted trajectory of movement is oriented towards the kitchen, and it appears from the video that he only briefly glances at Rose while continuing to move towards it. He keeps doing so throughout lines 3-4 while responding minimally to the complex turn, and only in fact to the thanking part rather than to the compliment. 
The turn produced by Rose does not contain any distinct prosodic features but is produced in a rather flat prosody. However, Rose's bodily orientation is rather distinct: She walks towards Alex and then stops in front of him, and gazes directly at him. As Alex produces a rather minimal response, Rose tags on a further component Were you happy? to pursue a stronger response. Alex indeed stops at the door to respond to this.

We may briefly summarize the design of compliments in the database. They exhibit a format-like vocal/grammatical form which includes extreme case formulations and intensifiers that strengthen the evaluation. They are frequently prosodically marked (see also Examples 4 and 5 below) to strengthen the affective tone and/or to add further emphasis to the compliment. Gazing at the recipient and thus seeking mutual gaze appears to be a relatively constant bodily-visual feature in the data and acts towards making a response due from the recipient. Compliment producers also at times pursue a response to their compliment by vocal means (seriously \#. in Example 2, Were you happy? in Example 3). Often some bodily-visual features such as hand gestures, head shakes and eyebrow flashes, or withholding other action such as drinking (see Example 4 below), are involved in the compliment's delivery. In terms of sequential position, compliments are found in the midst of sequences of actions, as part of the ongoing activities, and even in sequence-initial position, as in Example 3, they arise from the immediate interactional contingencies.

Even though compliment actions are not highly frequent in our data (in 8 hours of data we find 21 cases), they are nevertheless all done through employing a couple of verbal formats that show an "almost total lack of originality" (Manes and Wolfson 1981: 115, albeit that our formats are different from the ones observed by them; cf., however, Shaw \& Kitzinger 2012: 241 for institutional data on 112 compliments produced by one participant, which show a broad syntactic range and semantic diversity). However, even though in all our cases the verbal format is fitted to the particular social action of complimenting, their prosody and bodily production are an essential part of action construction (see Fox 2007). We also acknowledge that actions may differ in this respect: Offers and fulfillments of requests, for example, may rely on embodiment to a much larger extent and are sometimes implemented solely through bodily actions (Kärkkäinen \& Keisanen 2012; Rauniomaa \& Keisanen 2012).

\subsubsection{Responses to compliments}

This section discusses recipient reactions to compliments, focusing on how compliment responses are constructed with language and the body. According to Pomerantz (1978), rejections of prior compliments are not clearly preferred over acceptances. This inbetween nature of compliment responses is argued to display the recipients' orientation towards avoidance of self-praise, while also displaying orientation towards showing their appreciation of the compliment. In line with these findings, the recipients of compliments in the current database generally do not show unambiguous acceptance of, or agreement with, the compliment. As we have already seen, the vocal responses may be quite minimal. With respect to embodied actions, recipients' bodily movements are likewise rather subdued. The most recurrent feature of compliment responses is the embodied action of avoiding or breaking mutual gaze (if one has been established) with the compliment producer, and turning one's head and gaze down towards one's own lap or some object at hand. This forms a central embodied means found in compliment 
responses and it will be argued that such withdrawal of gaze is used for displaying avoidance of self-praise.

In Example 4 below, three recipients are complimented on their appearance. Compliments that relate to the recipients' appearance are rather infrequent in the current database, as there are only two other similar cases in the data. It is more typical that the compliments are connected to recipients' other personal qualities or their actions. This seems to reflect the functions of compliments in the data: As mentioned above, the majority of them are reactions to immediately prior discourse, rather than being produced as initial compliments, for example, in first encounters, where compliments on personal appearance may provide a convenient conversational topic. The example below presents one potential case of an initial compliment that does not directly relate to prior talk, but which nevertheless thematically arises from it.

The example involves three main participants, Edith (on the left in the left frame in Figure 6), Jenny (in the middle) and Viola (on the right). The fourth person in this segment, Cassandra (behind Viola on the background), has just entered the flat where the video recording is going on. Viola and Cassandra are non-native speakers of English, Edith is Australian and Jenny is American. As Cassandra tries to enter her room, she faces some difficulty, as the tripod for the video camera is partly blocking the entryway. After some negotiation, Cassandra manages to go around the tripod. Edith has previously gotten up to help her. During line 2 Edith returns to the table, where Jenny and Viola have remained seated.

(4) Oulu Video Corpus of English, 002 Always in Oulu 〈00:10:10〉

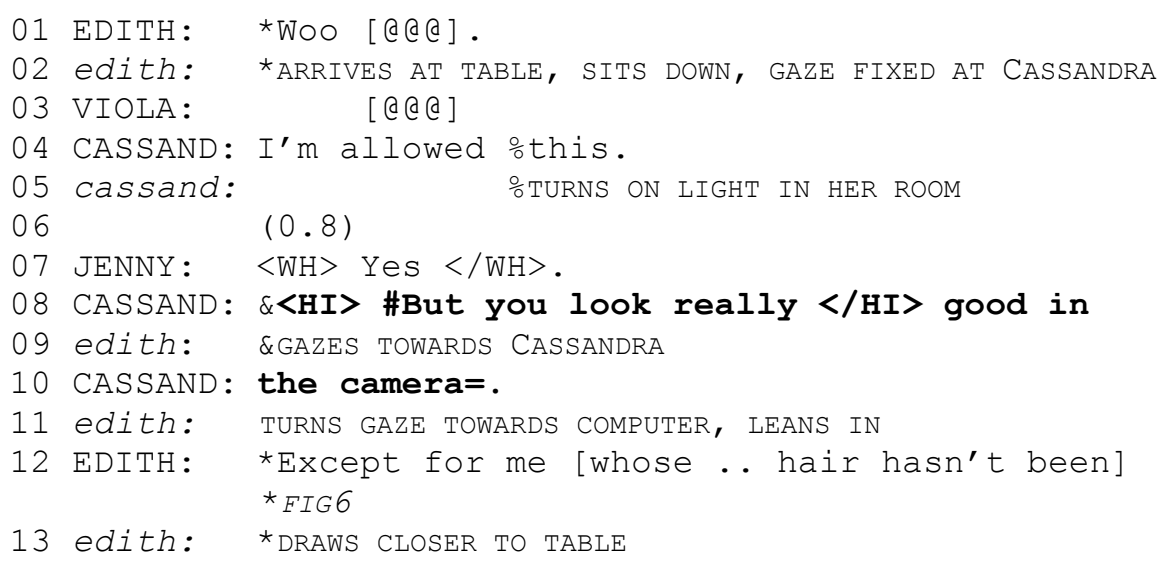




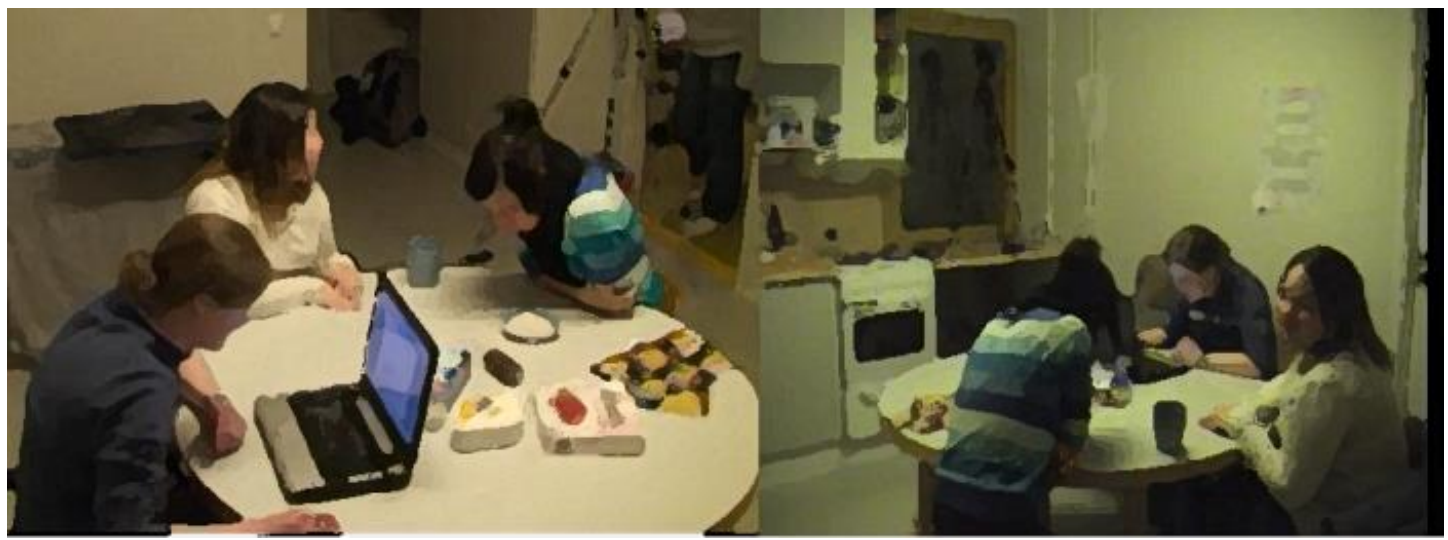

Figure 6. Edith gazing at the computer (from two different camera angles)
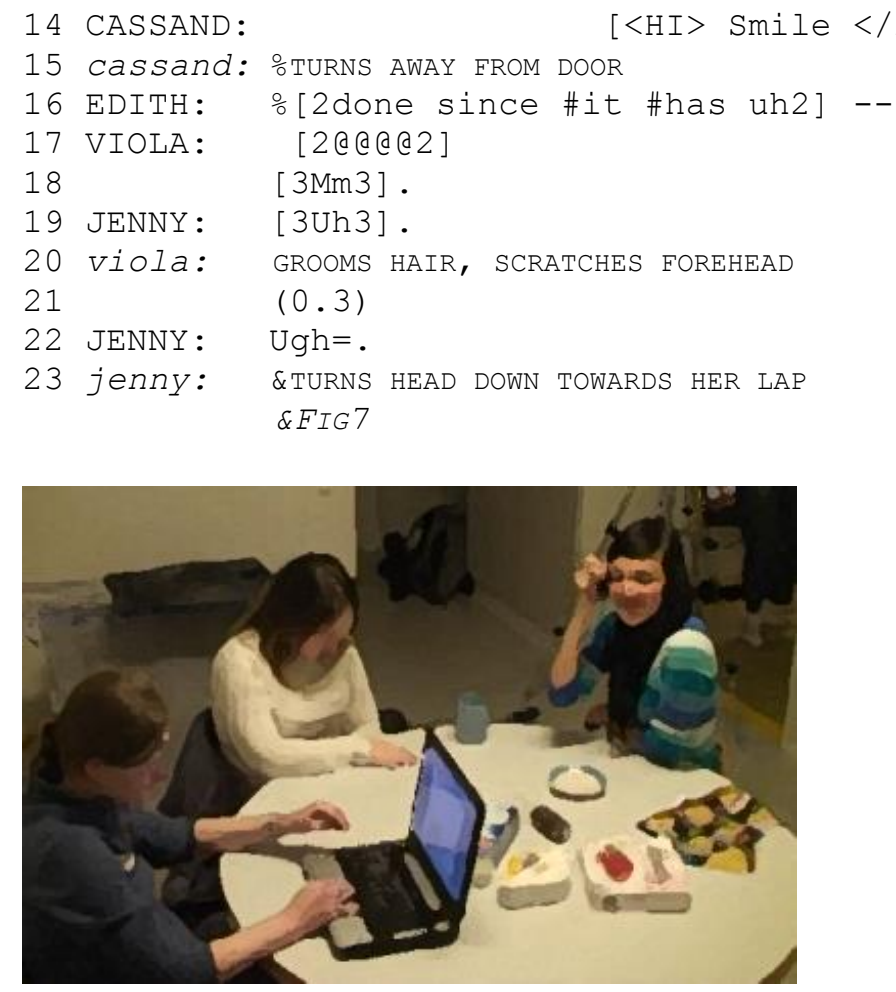

Figure 7. Jenny gazing towards her lap

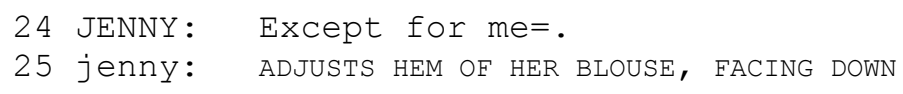

In line 4, Cassandra asks (standing inside her room) if she is allowed to turn on the light, apparently being sensitive to the fact that the light might interfere with the recording. Jenny grants her permission (line 7). At this point Cassandra produces a compliment, $\langle H I\rangle$ \#But you look really $\langle/ H I\rangle$ good in the camera=. (lines 8, 10). The compliment directs the attention to the other participants and the fact that they are being video-recorded. The turn-initial but (which is here, however, based on uncertain hearing as indicated by \#) has been observed to indicate that the speaker returns to some previous line of talk that was suspended because of an intervening activity, and thereby also to indicate some contrast with prior talk (Schiffrin 1987; Sorjonen 1994 for Finnish mutta 'but'). Here the use of turn-initial but can be taken to indicate that the recording 
situation was interrupted by Cassandra's entry into her room, but that now the compliment attempts to initiate a return to that. In this sense, Cassandra's compliment may also be seen as an initial compliment which does not directly relate to the immediately prior talk. The compliment evaluates in positive terms how Edith, Viola and Jenny look: Nice and suitable for being recorded. During the production of the compliment, Cassandra's upper body is not visible on camera, but her lower body is turned towards the others (see Figure 6), and stays there until she turns away at the end of the added instruction $\langle H I\rangle$ Smile $\langle/ H I\rangle$ (line 14). The compliment and the instruction are prosodically marked as indicated by $\langle\mathrm{HI}\rangle\langle/ \mathrm{HI}\rangle$. The compliment turn begins in rather high pitch and ends on mid-level, indicating Cassandra's affective involvement.

Edith's response to the compliment Except for me whose .. hair hasn't been done since \#it \#has uh -- (lines 12,16) amounts to a self-deprecation. Rather than accepting the compliment, Edith restricts its area of application by excluding herself, thus conforming to the preference of avoiding self-praise (Pomerantz 1978). Edith has intently gazed towards Cassandra during the production of the compliment, but at the end of it, she sharply withdraws her gaze, turning it towards the computer (lines 11, 13, Figure 6).

Even though Viola, the second recipient, does not respond vocally to the compliment, she self-grooms by adjusting her hair and scratching her forehead, glancing towards the other video camera while doing so (line 20, Figure 7). This amounts to an ambivalent response which does not display clear acceptance or rejection. In overlap with her, the third recipient Jenny produces another self-deprecating vocal response to the compliment that mirrors the one produced by Edith. The vocal part Ugh=. Except for $m e=$. (lines 22, 24) is accompanied by a similar withdrawal of gaze as was done by Edith. Jenny has gazed towards Cassandra during Edith's response (Figure 6), but as Edith is finishing her response to the compliment, Jenny first turns her gaze towards Edith, and then towards her lap (line 23, Figure 7). She then adjusts the hem of her blouse (line 25). In addition to the changing gaze direction, in this case the selfgrooming or other adjustments of appearance are further embodied means for constituting 'modesty' or 'compliment resistance' in order to display avoidance of selfpraise in compliment responses.

The next case is another example of a compliment response where avoidance of direct eye contact constitutes the main embodied means of responding. The family are having dinner, with the mother Rose and her son Alex's girlfriend Jeannine talking about men and shopping. Jeannine has been talking about a male friend of hers who does not like shopping. The compliment is produced by Laura and it is targeted at her brother Alex.

(5) Oulu Video Corpus of English, 008 Piano Dinner 〈00:13:40>

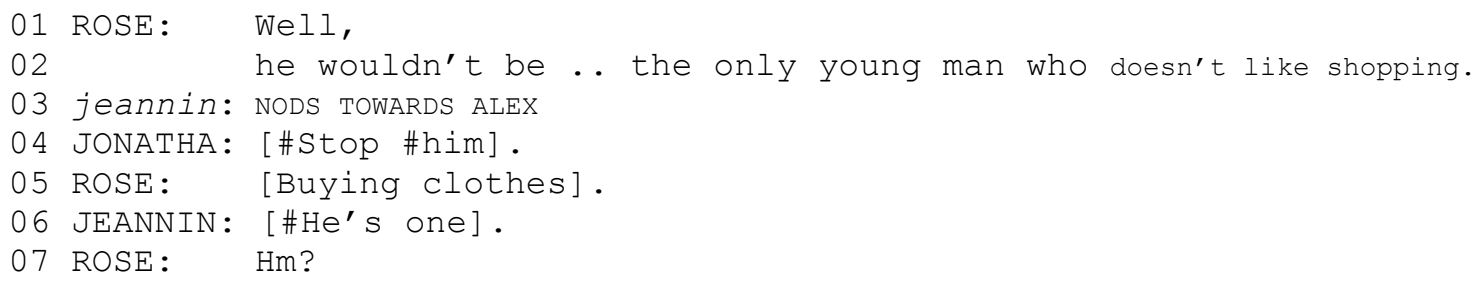




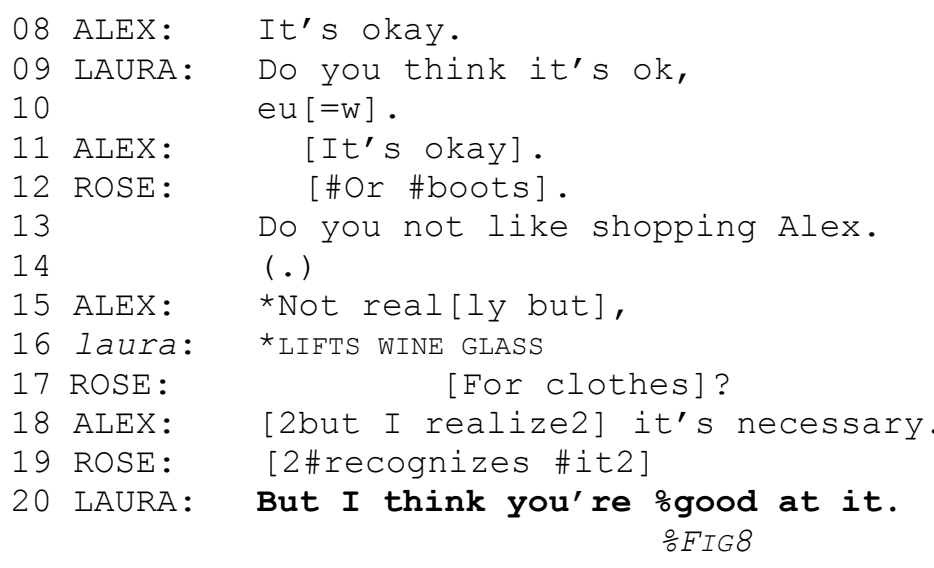

\section{1 laura \&DRINKS WINE}

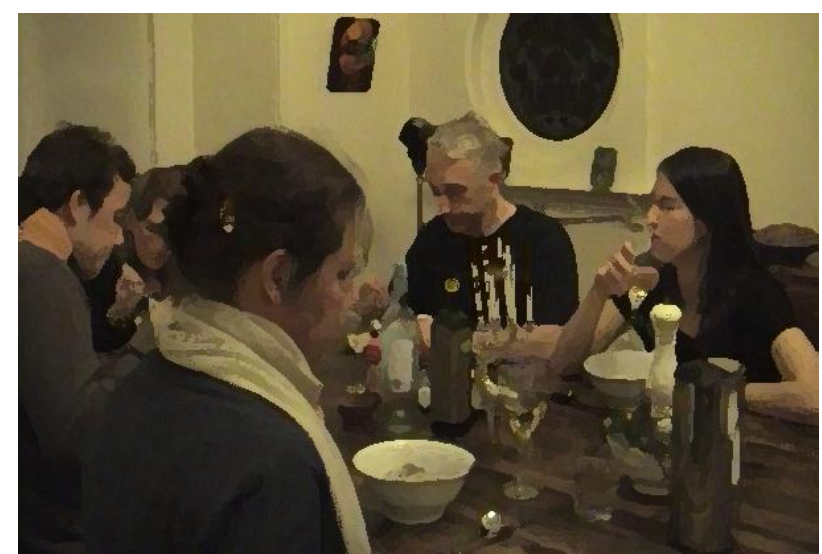

Figure 8. Laura holding up the wine glass, gazing at Alex

22 alex: \&KEEPS CATCHING SPAGHETTI ONTO HIS FORK AND LIFTING IT FROM PLATE

23 ALEX: \&Well, it's- I think it's just that, $\&$ FIG 9

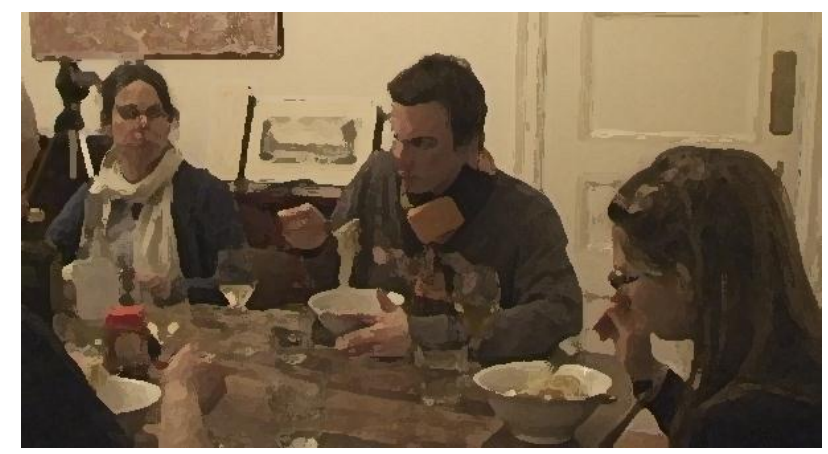

Figure 9. Alex directs gaze towards spaghetti
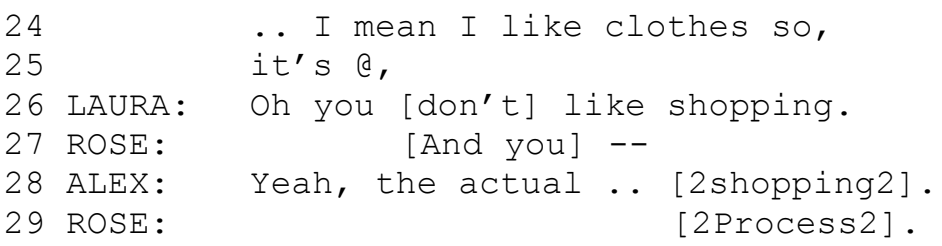
Rose and Jeannine are involved in the topic of men and shopping, while father Jonathan focuses on the wine that they are all drinking. Laura and Alex are variously involved in these two topics. In reaction to Rose's turn in line 1, Jeannine nods towards Alex (line 3) and names him (line 7), while also pointing towards him, as an example of a young man who does not like shopping. This gives rise to Rose's question Do you not like shopping Alex (line 13). Alex replies in the negative, but acknowledges shopping as a necessary thing to do (lines 15,18 ). In response to Alex's non-enthusiastic approach to shopping, Laura compliments her brother, But I think you're good at it, (line 20). She gazes at Alex while doing so, but Alex is not making eye contact with her and continues to eat the spaghetti on his plate. Laura has just lifted her wine glass, but refrains from drinking until after she has produced the compliment (Figure 8, Laura is sitting on the right). The compliment is delivered in a rather high pitch and a fall-rise intonation pattern, and with a rather strong emphasis on the accented syllable good, as well as prefaced by but, thus suggesting a contrast to how Alex views himself as a shopper.

Alex's response to the compliment is not a full acceptance but designed in a way that orients to both acceptance and avoidance of self-praise as relevant next actions. Alex starts out with well to project that the response is not a fully accepting one (Pomerantz 1984), and after some hesitation he offers a possible reason for being a good shopper, said with a laugh token: He likes clothes (line 24-25). He nevertheless scales down the assertion in the compliment by adding it's just that (line 23) (Pomerantz 1978). During the compliment response he does not lift his gaze from the plate but continues to occupy himself with eating (Figure 9).

In both Examples 4 and 5 the material environment provides the compliment recipients with something to occupy themselves and thereby display less than full engagement in receiving the compliment, as is appropriate when orienting to the avoidance of self-praise. In Example 4 Edith turns to the computer, and in Example 5 Alex continues to eat his dinner. It does not seem inconsequential that they switch (Example 4) or continue (Example 5) their embodied orientation to other incipient or ongoing activities, as such orientations are observable in other cases in the database (see also Example 3). This seems to be one further means to construct compliment responses: The recipient's embodied orientation to other activities accompanies or precedes the verbal response to the compliment (if there is one), and may form a part of the social action format for a response to a compliment.

In a similar vein, if the compliment is a reaction to the recipient's ongoing line of action, the recipient may appear to ignore it and just proceed with their original line of action. The final example in this section provides an illustration of this. The compliment is produced in response to an ongoing telling sequence, where Rukmini is telling the others about her plans for the future.

(6) Oulu Video Corpus of English, 012 Oh My God 〈00:14:07〉

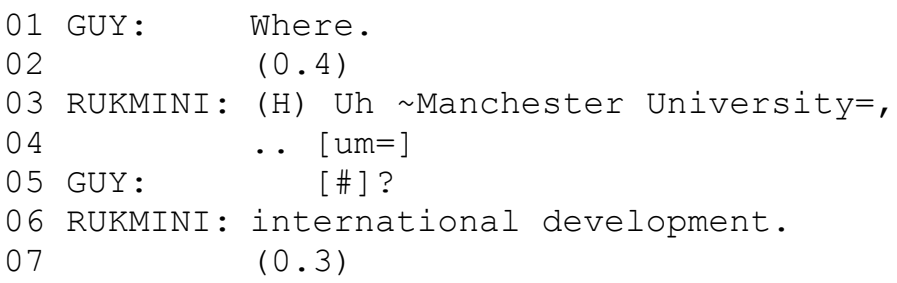



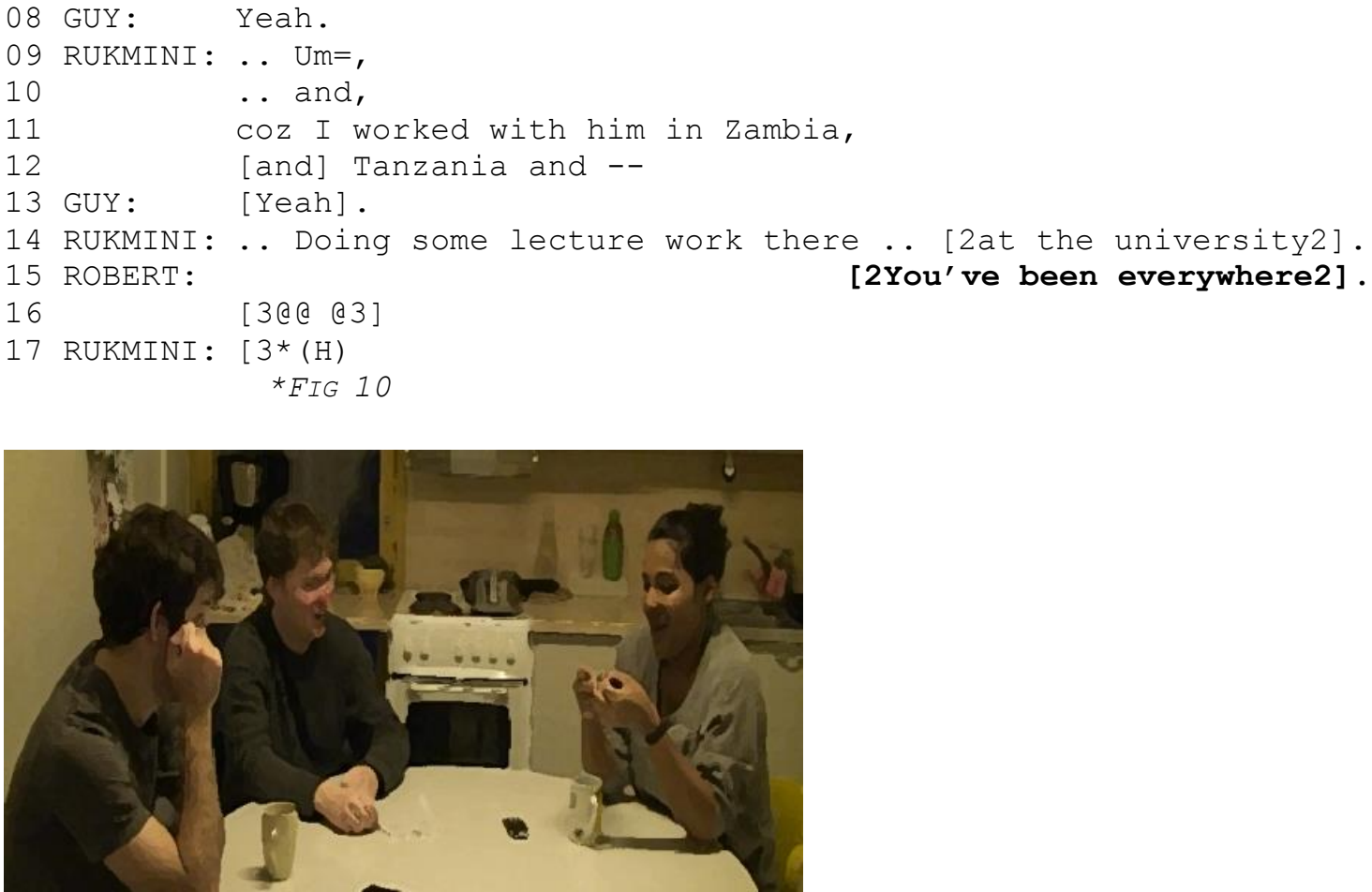

Figure 10. Rukmini gazes down on the keys in her hands and smiles

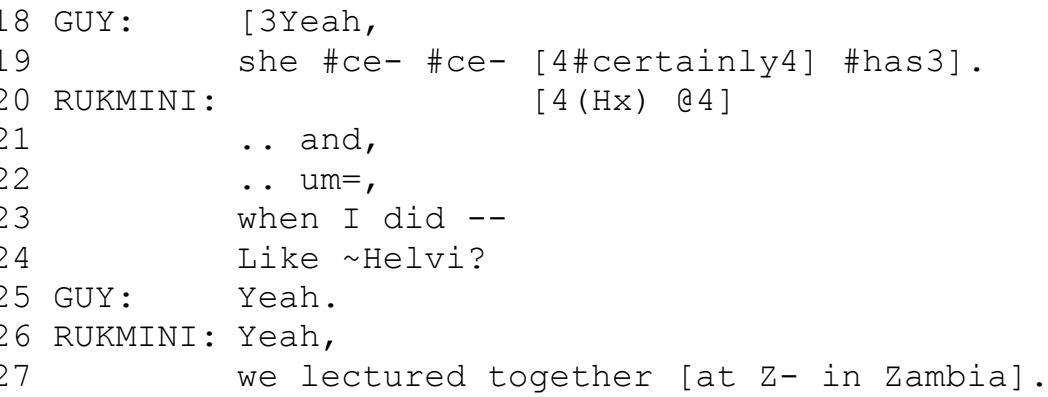

Some three minutes prior to this extract, Guy has asked Rukmini about a course that she was intending to attend after finishing her current studies. All three participants are studying at the university, though both Guy and Rukmini have already completed a master's degree. After Guy's question the conversation has veered to other issues, but here Rukmini returns to it. She begins by explaining how a vice-chancellor of her university has recommended her for this course, and in response to Guy's question in line 1, provides further information by naming the university and the faculty where the course is organized (lines 3,6). Rukmini then provides a reason why the vice-chancellor would recommend her, by reporting about their collegial past in doing lecture work together in different African countries (lines 11-12, 14). Rukmini positions herself here as someone already having rather extensive experience with academic work, and this is what Robert's upcoming compliment seems to partly pick up on.

Robert produces the compliment You've been everywhere (line 15) with a rather neutral tone of voice but in a relatively high pitch and a noticeable intonation pattern that puts affective emphasis on the word everywhere. The compliment is accompanied by slight headshakes, a smile and a few faint tokens of laughter (line 16). Rukmini's prior account has been addressed to Guy, and her gaze has been directed towards him 
throughout the turn. However, at the end of the compliment she briefly turns her gaze towards Robert but moves it away almost immediately, towards the keys in her hands, and smiles (line 17, Figure 10). This constitutes her embodied response to the compliment. In addition to turning her gaze down and smiling, Rukmini inhales (line 17) and exhales (line 20) during Guy's turn in lines 18-19. Guy builds on Robert's prior turn and recognizably produces a second compliment. There is thus no explicit vocal response to either compliment, and Rukmini's breathing sounds may be seen to project the continuation of her telling. Rukmini proceeds to resume her prior telling with ..and, $. . u m=$, (lines 21-22). Such vocalizations have been shown to indicate that what follows is not to be treated as relating to immediately prior talk (here the compliment), but that it relates to some earlier talk produced by the same speaker (Local 2004). As evidence of initiating such 'back-connecting', Rukmini provides another example of her teaching experience, by mentioning a person Helvi that Guy also knows (lines 23-24). Similar to Example 2, where the compliment is produced in response to an ongoing telling, the compliment is here equally received with embodied means only. There is no vocal acknowledgement and the compliment is sequentially bypassed by resuming the telling.

In sum, the majority of compliments in our data receive a minimal vocal response or an embodied response only (11 cases). In these cases, the material environment often provides the compliment recipients with something to occupy themselves and thereby display less than full engagement in receiving the compliment. Thus, in most cases the response is not clearly an acceptance or a rejection. Only three compliments receive a clear verbal acceptance, which is a notable difference with Shaw \& Kitzinger's (2012: 232) dataset, where about half of the compliments were accepted. Explicit verbal rejections, verbally ambivalent responses and verbal responses that take up some other aspect than the compliment in the compliment turn cover the remaining seven cases. As a whole, the verbal materials in responses to compliments do not fall into clear linguistic formats (see also Shaw \& Kitzinger 2012).

As compliments have a conflicting preference structure in that neither agreements nor disagreements are clearly preferred, the role of gaze direction in constructing disagreement or agreement with the prior compliment is not as clear as in assessment sequences, where cut-off gaze has been shown to precede a divergent response to a prior assessment (Haddington 2006). In the current dataset the recipients are observed to turn (or keep) their gaze away in disagreeing responses (e.g. Example 4 Except for me) as well as in responses that do not have a clear polarity due to conflicting preferences (e.g. Example 5 Well, it's- I think it's just that, .. I mean I like clothes so,), or include minimal vocal elements (e.g. Example 6). In these, gaze aversion forms the main means of responding. This provides some initial indication that different action types are designed with different bodily constellations, but there clearly is a need for more research on the role of embodied actions in relation to different kinds of social actions, also in relation to their preference structures (see also Rossano 2013).

This section has discussed compliment responses and shown that the clearest and most frequent bodily-visual display which occurs in compliment responses in the current database is the recipients' avoiding or breaking mutual gaze (if one has been established) with the compliment producer. 


\section{Conclusion}

This paper has offered an analysis of the interplay of language and embodied actions in turns-at-talk that are used for evaluating some personal attribute or action of (a) copresent participant(s) in the present situation and for receiving such evaluation.

We will here offer some concluding remarks on how multimodality enters into the construction of social action formats, and in particular of those observed for making compliments and responses to compliments. As we have seen, the degree to which linguistic actions are formulaic may vary, such that responses to compliments are done in less format-like language than compliments. It was established that the most recurrent embodied feature of compliments and their responses was the seeking of mutual gaze with the compliment recipient and the avoiding or breaking of mutual gaze with the compliment producer. Compliment producers seek mutual gaze in order to pursue a response, while recipients typically avoid mutual gaze by turning their head and gaze down towards their lap or some object at hand in order to display resistance towards self-praise. Thus, we may claim that gaze direction is constitutive of these actions, in the same way as suggested by Fox (2007: 312) with respect to Hayashi's (2003) study of anticipatory completions in Japanese: When the speaker was looking at the recipient, his utterances were treated as inviting anticipatory completion, whereas when the speaker was looking away, the utterances were not treated as such. We have further seen that affect is regularly expressed in compliments through bodily means and prosody. It is perhaps a more open question how regularly body position, hand gestures and facial expressions are constitutive of the action of compliments, but they may also impact the recipient's response to the actions concerned. In addition, many studies show that prosody may constitute the action of a turn and thus be part of the grammatical format of the turn (Fox 2007: 312, see the summary of such studies provided by her); in our study we have shown that prosody is an integral part of the social action formats for complimenting (even though perhaps less so of compliment responses). Finally, the use of the material environment was seen to be an essential part of the compliment responses - the use of the material environment may thus have to be seen as part of the social action format.

We may conclude that social action formats are multimodal constructs, even if to a varying degree. As we have noted, actions may differ in this respect and some actions may even be implemented solely through bodily actions, without any vocal component. Even though we have focused here on compliments produced with language, it is conceivable that they may be produced with a hand gesture alone, or a combination of hand gesture and facial expression, even though less commonly perhaps. And we have seen examples of compliment responses which are done through embodied actions alone.

Finally, we may reflect on our view of grammar and whether grammar should incorporate social action formats and, therefore, multimodality. We understand grammar to mean the knowledge of language that we use when talking, and as we stated above, we approach grammar as an inventory of format-like and emergent patterns of interaction. Talk-in-interaction necessarily includes not just linguistic form, but also prosody, embodiment, and the material context. Thus, the action-based approach adopted here enables full inclusion of embodiment and the material context in our analyses, and their treatment as equally important resources alongside language. We have shown how participants orient to bodily actions and the use of objects and artifacts 
as central for action formation, here especially for responses to compliments. If one were to start with language, even though an equally feasible option, it would privilege this mode above others and might prevent us from seeing that distinct bodily actions alone can implement actions such as responses to compliments.

Fox (2007: 312) claims that "[o]ne of the properties of grammar that allows it to function as a public embodiment of action is the existence of grammatical formats fitted to particular social actions." Even though compliments do seem to have a rather formatlike linguistic shape, language is nevertheless only one resource that participants have at their disposal. Fox further argues, as we do as well, that embodied actions and vocal prosody "are always visually and/or auditorily available to recipients" (2007: 312), and are an integral part of the production of any utterance. We feel that it is this kind of knowledge that studies of language use, such as practice-based grammars, should incorporate.

\section{Appendix A}

Transcription conventions (based on Du Bois et al. 1993)

Intonation unit (one line is one IU)

\{carriage return\}

Truncated intonation unit

Truncated word

Final intonation contour

Continuing intonation contour

Appeal intonation contour

$-$

Speech overlap (numbers index overlaps)

Short pause $(<0.2$ seconds)

Pause ( $>0.3$ seconds)

Tongue click

Real name/place name

$-$

Changed name/place name

Exhalation

.

Inhalation

[ ], [2word2]

Laughter (one pulse)

(TSK)

Name

$\sim$ Name

(Hx)

(H)

Higher pitch level

@

Forte: loud

$<\mathrm{HI}>$ words $\langle/ \mathrm{HI}\rangle$

Whispered

$\langle\mathrm{F}\rangle$ words $\langle/ \mathrm{F}\rangle$

Uncertain hearing

Indecipherable syllable

$\langle\mathrm{WH}\rangle$ words $\langle/ \mathrm{WH}\rangle$

\#two \#words

\# 


\section{References}

Bavelas, J.B., L. Coates, and T. Johnson (2002) Listener responses as a collaborative process: The role of gaze. Journal of Communication 52: 566-580.

Couper-Kuhlen, Elizabeth (2012) On affectivity and preference in responses to rejection. In E. Kärkkäinen, and J. Du Bois (eds.), Stance, Affect, and Intersubjectivity in Interaction: Sequential and Dialogic Perspectives. Special issue of Text \& Talk 32-4: 453-475.

Couper-Kuhlen, Elizabeth, and Sandra Thompson (2005) A linguistic practice for retracting overstatements: 'Concessive repair'. In A. Hakulinen, and M. Selting (eds.), Syntax and Lexis in Conversation: Studies on the Use of Linguistic Resources in Talk-in-Interaction. Amsterdam: John Benjamins Publishing Company, pp. 257-288.

Du Bois, John, and Elise Kärkkäinen (2012) Taking a stance on emotion: Affect, sequence, and intersubjectivity in dialogic interaction. In E. Kärkkäinen, and J. Du Bois (eds.), Stance, Affect, and Intersubjectivity in Interaction: Sequential and Dialogic Perspectives. Special issue of Text \& Talk 32-4: $433-451$.

Du Bois, John, Stephan Schuetze-Coburn, Susanna Cumming, and Danae Paolino (1993) An outline of discourse transcription. In J.A. Edwards, and M.D. Lampert (eds.), Talking data: Transcription and coding in discourse research. Hillsdale, NJ: Lawrence Erlbaum, pp. 45-87.

Fox, Barbara A. (2000) Micro-syntax in conversation. Paper presented at Interactional Linguistics Conference, Spa, Belgium, September 2000.

Fox, Barbara A. (2007) Principles shaping grammatical practices: An exploration. Discourse Studies 9.3: 299-318.

Golato, Andrea (2002) German compliment responses. Journal of Pragmatics 34: 547-571.

Goodwin, Charles (2000) Action and embodiment within situated human interaction. Journal of Pragmatics 32: 1489-1522.

Goodwin, Charles, and Marjorie Harness Goodwin (1987) Concurrent operations on talk: Notes on the interactive organization of assessments. IPrA Papers in Pragmatics 1.1: 1-54.

Goodwin, Charles, and Marjorie Harness Goodwin (1992) Assessment and the construction of context. In A. Duranti, and C. Goodwin (eds.), Rethinking context. Language as an interactive phenomenon. Cambridge: Cambridge University Press, pp. 147-190.

Haddington, Pentti (2006) The organization of gaze and assessments as resources for stance taking. Text \&Talk 26.3: 281-328.

Hayashi, Makoto (2003) Joint utterance construction in Japanese converstion. Amsterdam: John Benjamins Publishing Company.

Heritage, John (2002) Oh-prefaced responses to assessments: A method of modifying agreement/disagreement. In C. Ford, B.A. Fox, and S. Thompson (eds.), The Language of Turn and Sequence. New York: Oxford University Press, pp.196-224.

Heritage, John, and Geoffrey Raymond (2005) The terms of agreement: Indexing epistemic authority and subordination in assessment sequences. Social Psychology Quarterly 68.1: 15-38.

Hutchby, Ian, and Robin Wooffitt (2008) Conversation Analysis, 2nd edition. Cambridge: Polity Press. 
Keisanen, Tiina (2012) "Uh-oh, we were going there": Environmentally occasioned noticings of trouble in in-car interaction. Semiotica 191.1/4: 199-224.

Keisanen, Tiina, and Elise Kärkkäinen (2014) Stance. In Klaus P. Schneider, and Anne Barron (eds.), Pragmatics of Discourse. Handbook of Pragmatics [HOPS]. Berlin: Mouton de Gruyter, pp. 295-322.

Kärkkäinen, Elise, and Tiina Keisanen (2012) Linguistic and embodied formats for making (concrete) offers. Discourse Studies 14.5: 1-25.

Lindström, Anna, and Lorenza Mondada (2009) Assessments in social interaction: Introduction to the special issue. Research on Language and Social Interaction 42.4: 299-308.

Local, John (2004) Getting back to prior talk: And-uh(m) as a back-connecting device. In E. CouperKuhlen, and C. Ford (eds.), Sound patterns in interaction: Cross-linguistic studies of phonetics and prosody for conversation. Amsterdam: John Benjamins Publishing Company, pp. 377-400.

Manes, Joan, and Nessa Wolfson (1981) The compliment formula. In F. Coulmas (ed.), Conversational Routine: Explorations in Standardized Communication Situations and Prepatterned Speech. The Hague: Mouton Publishers, pp. 115-132.

Nevile, Maurice (2004) Beyond the black box. Talk-in-Interaction in the Airline Cockpit. Aldershot: Ashgate.

McClave, Evelyn (2000) Linguistic functions of head movements in the context of speech. Journal of Pragmatics 32: 855-878.

Mondada, Lorenza (2009) The embodied and negotiated production of assessments in instructed actions. Research on Language and Social Interaction 42.4: 329-361.

Pomerantz, Anita (1978) Compliment responses. Notes on the co-operation of multiple constraints. In J. Schenkein (ed.), Studies in the Organization of Conversational Interaction. New York: Academic Press, pp. 79-112.

Pomerantz, Anita (1984) Agreeing and disagreeing with assessments: Some features of preferred/dispreferred turn shapes. In M. Atkinson, and J. Heritage (eds.), Structures of Social Action. Studies in Conversation Analysis. Cambridge: Cambridge University Press, pp 57-101.

Pomerantz, Anita (1986) Extreme case formulations: A way of legitimizing claims. Human Studies 9: 219-229.

Rauniomaa Mirka, and Tiina Keisanen (2012) Two multimodal formats for responding to requests. Journal of Pragmatics 44.6-7: 829-842.

Rossano, Federico (2013) Gaze in conversation. In J. Sidnell, and T. Stivers (eds.), The Handbook of Conversation Analysis. Malden: Wiley-Blackwell, pp. 308-329.

Ruusuvuori Johanna, and Anssi Peräkylä (2009) Facial and verbal expressions in assessing stories and topics. Research on Language and Social Interaction 42.4: 377-394.

Schegloff, Emanuel (1986) On some gestures' relation to talk. In J.M. Atkinson, and J. Heritage (eds.), Structures of Social Action. Studies in Conversation Analysis. Cambridge: Cambridge University Press, pp. 266-296.

Schegloff, Emanuel (2007) Sequence Organization in Interaction. Cambridge: Cambridge University Press. 
Scheibman, Joanne (2001) Local patterns of subjectivity in person and verb type in American English conversation. In J. Bybee, and P. Hopper (eds.), Frequency and the Emergence of Linguistic Structure. Amsterdam: John Benjamins Publishing Company, pp. 61-89.

Schiffrin, Deborah (1987) Discourse Markers. Cambridge: Cambridge University Press.

Shaw, Rebecca, and Celia Kitzinger (2012) Compliments on a home birth helpline. Research on Language and Social Interaction 45.3: 213-244.

Sorjonen, Marja-Leena (1989) Vuoronalkuiset konnektorit: Mutta. [Turn-initial connectors: But]. In A. Hakulinen (ed.), Suomalaisen keskustelun keinoja I. Kieli 4. Helsinki: Finnish Department, University of Helsinki, pp. 162-176.

Stivers, Tanya, and Frederico Rossano (2010) Mobilizing response. Research on Language and Social Interaction 43.1: 3-31.

Streeck, Jürgen, Charles Goodwin, and Curtis LeBaron (2011) Embodied interaction in the material world. An introduction. In J. Streeck, C. Goodwin, and C. LeBaron (eds.), Embodied Interaction. Language and Body in the Material World. Cambridge: Cambridge University Press, pp. 1-26.

Wagner, Johannes, and Rod Gardner (2004) Introduction. In R. Gardner, and J. Wagner (eds.), Second Language Conversations. London: Continuum, pp. 1-17.

TIINA KEISANEN is a University Lecturer at the University of Oulu. Her research interests include the multimodality of interaction and the relationship between language and social interaction.

Address: English Philology, Faculty of Humanities, P.O. Box 1000, 90014 University of Oulu, Finland. E-mail: tiina.keisanen@oulu.fi

ELISE KÄRKKÄINEN is Professor of English Philology at the University of Oulu. Recently she has conducted a research project on the multimodal analysis of recurrent conversational routines used for the accomplishment of social actions in everyday and more planned varieties of English.

Address: English Philology, Faculty of Humanities, P.O. Box 1000, 90014 University of Oulu, Finland. E-mail: elise.karkkainen@oulu.fi 